Artigos

\title{
Abismos do reconhecimento \\ O legado sociofilosófico de Jean-Jacques Rousseau
}

\author{
Abysses of recognition \\ The sociophilosophical legacy of Jean-Jacques Rousseau
}

Axel Honneth*

\begin{abstract}
Resumo: O texto se ocupa com a questão da interpretação da obra de Jean-Jacques Rousseau, em particular com suas referências sobre a dependência constitutiva em relação aos outros. Vista negativamente na crítica da cultura, mas positivamente nos esboços de um contrato social, o lugar dessa dependência constitutiva da confirmação e estima por parte dos outros está vinculada ao significado dado ao "amor próprio" nos diferentes textos; mas ela abre a possibilidade de interpretar Rousseau como um teórico do reconhecimento. $\mathrm{O}$ autor acompanha Rousseau em seu desenvolvimento teórico até o ponto em que ele se tornou consciente das exigências de uma forma sociocontratual, igualitária do reconhecimento mútuo, para depois expor a enorme influência que a ideia bipolar de Rousseau a respeito do reconhecimento social exerceu sobre a teoria social da modernidade: em sua variante negativa, a profunda necessidade dos seres humanos de sobrepujar os respectivos cossujeitos no grau de estima social, reinterpretada por Kant como sendo a força motriz do progresso cultural e social, e em sua variante positiva, o respeito mútuo entre iguais, desenvolvido por Fichte e Hegel na direção de uma teoria do reconhecimento relacionada ao direito e à moralidade. No final, Honneth discute o ceticismo com que Rousseau sempre viu a dependência de outros contida no "amor próprio", deixando sem solução definitiva a tensão entre a ideia estoica de uma independência pessoal de toda avaliação alheia e a ideia intersubjetivista de uma profunda dependência do outro. (Resumo do editor).
\end{abstract}

Palavras-chave: Rousseau. Reconhecimento. Amor próprio. Intersubjetividade. Interpretação filosófica.

\begin{abstract}
The text deals with the question of the interpretation of the work of JeanJacques Rousseau, in particular with his references to the constitutive dependence on

* Doutor e livre-docente em Filosofia, professor na Universidade de Frankfurt (Alemanha) e diretor do Instituto para Pesquisa Social. Principais publicações: Luta por reconhecimento (Editora 34), Verdinglichung (Suhrkamp), Sofrimento de indeterminação (Esfera Pública), Das Recht der Freiheit (Suhrkamp). Texto foi gentilmente cedido para publicação na Civitas pelo autor < honneth@em.uni-frankfurt.de>. Tradução do alemão, com apoio do CNPq (edital 15/2011): Luis Marcos Sander.
\end{abstract}

\begin{tabular}{|l|l|l|l|l|l|}
\hline Civitas & Porto Alegre & v. 13 & n. 3 & p. 563-585 & set.-dez. 2013 \\
\hline
\end{tabular}


others. Viewed negatively in the critique of culture, but positively in outlines of a social contract, the place of this constitutive dependence of confirmation and esteem from others is linked to the meaning given to "self-love" in different texts, but it opens the possibility of interpreting Rousseau as a theorist of recognition. The author follows Rousseau in his theoretical development to the point where he became aware of the requirements of an egalitarian social and contractual form of mutual recognition, and then expose the enormous influence that bipolar Rousseau's idea about the social recognition exerted on the modern social theory: in its negative variant, the basic need of human beings to overcome their fellow citizens in the degree of social esteem, reinterpreted by Kant as being the driving force of social and cultural progress, and in its positive variant, the mutual respect between equals, developed by Fichte and Hegel toward a theory of recognition related to law and morality. In the last part of the text, Honneth discusses the skepticism with which Rousseau ever has seen the dependence on others contained in the "self esteem", leaving without a definitive solution to the tension between the Stoic idea of a personal independence of all evaluation by others and the idea of a profound dependence on others. (Editor's abstract).

Keywords: Rousseau. Recognition. Self-love. Intersubjectivity. Philosophical interpretation.

Quando, em 1932, Ernst Cassirer (1989) publicou seu grande ensaio sobre O problema Jean-Jacques Rousseau, ele decerto tinha certeza de ter encontrado definitivamente a chave para uma compreensão integral da escabrosa obra do filósofo; hoje em dia, entretanto, 80 anos mais tarde, quando se comemora no mundo todo o $300^{\circ}$ aniversário de Rousseau, a proposta de Cassirer já está quase esquecida novamente, de modo que a pesquisa continua às voltas com o enigma de onde se deve buscar a unidade - se é que existe - nos diversos escritos, aparentemente contraditórios, do grande pensador. Nenhum outro autor filosófico da modernidade, talvez com a exceção de Nietzsche, provocou interpretações mais radicalmente opostas de sua obra, mas também nenhum outro continuou sendo, por isso mesmo, de maneira tão constante o contemporâneo eternamente jovem, sempre provocador e inquietante. Dependendo da disposição mental e da situação história circunstancial, podia-se encontrar em Rousseau o antropólogo que apelava para o exemplo da natureza humana, o filósofo moral que, como os ingleses, ressaltava o "sentimento" ou o teórico da autodeterminação democrática que preparou o caminho para Kant. Se a época exigia outras priorizações filosóficas, podia-se descobrir em Rousseau o precursor de uma concepção totalitária de democracia, o ardoroso defensor da igualdade republicana ou o advogado de um ideal de autenticidade pessoal. Todas essas interpretações, por mais heterogêneas que fossem, tinham de se confrontar com o mesmo grande problema de só poder fazer referência a determinadas partes da obra e de colocar em segundo plano outras partes que 
se opunham a elas. Só muito poucos conseguiram, como Cassirer, apresentar uma proposta que fosse capaz de interpretar os diversos escritos e pensamentos do filósofo como etapas da realização de uma única ideia básica.

Cassirer (1989, p. 60ss) divisou esse ponto de fuga da obra na ideia de uma vontade humana capaz de autodeterminação apesar de todas as ameaças sociais e políticas, mas a pesquisa subsequente logo o contestou incisivamente nesse tocante. Nessa espécie de interpretação, que fazia de Rousseau um precursor direto de Kant, não só não eram suficientemente levados em conta os traços coletivistas no Contrato Social, mas também, e principalmente, desconsiderava-se o que se podia ler nos outros escritos sobre a dependência mútua dos sujeitos, e até sobre sua condição de estarem à mercê do outro em cada caso. ${ }^{1}$ Esse elemento da obra, que se enraíza no conceito de "amour propre", "amor próprio", constitutivo para o Segundo discurso (Rousseau 1755[2008]) e o Emílio (Rousseau, 1762[1998]), foi, por isso, colocado cada vez mais em primeiro plano nas interpretações mais recentes. Com isso, porém, de modo algum se obtinha uma chave para a identificação de uma ideia básica unificadora, assim como não se esclarecia de que maneira o diagnóstico pessimista de Rousseau a respeito de uma dependência crescente do ser humano moderno em relação à estima dos outros estaria ligado com os traços confiantes de seu esboço de um Contrato social (Rousseau, 1762[2003] - afinal, lá onde se tematizava o "amor próprio" se falava de modo perceptível apenas do perigo de uma total determinação externa dos sujeitos, ao passo que aqui, na parte construtiva da obra, atribuía-se subitamente aos mesmos sujeitos uma capacidade inviolável para a autolegislação. O avanço para uma concatenação dos dois elementos e, por conseguinte, para uma interpretação integral da obra só surgiu na pesquisa quando o conceito de "amour propre" foi diferenciado de tal maneira que, a partir de então, ele conseguia abranger uma variante negativa e também uma positiva. Com essa proposta, que decerto devemos ao estudo pioneiro de Nicholas Dent (1988), deu-se pela primeira vez a possibilidade de considerar a ideia de Rousseau a respeito de uma dependência constitutiva do outro como um gancho que unia as duas partes de sua obra na medida em que na crítica da cultura ela foi explicitada em sua versão negativa e, nos esboços de um contrato social, em sua versão positiva.

Entretanto, com essa nova interpretação conjunta se tinha alcançado muito mais do que o próprio Dent deve ter percebido inicialmente, pois, se se desse à sua interpretação apenas uma pequena virada adicional, podia-se

Elementos dessa crítica a Cassirer estão contidos, com vistas às divergências acentuadas no conceito de história, no artigo de Kelly (1968). 
desenvolver a partir dela, sem dificuldade, a suposição de que Rousseau, com seu conceito bipolar de "amor próprio", tornara-se, ao mesmo tempo, também o fundador de toda a tradição da teoria do reconhecimento. $\mathrm{O}$ passo para a tese com isso indicada, que, do ponto de vista da história do intelecto, é de um significado de certa maneira revolucionário, decerto foi dado pela primeira vez por Frederick Neuhouser em seu grande estudo Rousseau's theodicy of selflove (2012); ${ }^{2}$ segundo ele, a percepção de que os sujeitos humanos devem sua capacidade de ação social ao reconhecimento por parte de outros sujeitos não remonta, como se supunha até agora, a Hegel, e sim a Rousseau. A importância dessa concepção e a extensão da redefinição da obra por ela causada só podem ser avaliadas plenamente quando se tenta tomar consciência, mais uma vez, da distância em relação à interpretação conjunta apresentada por Cassirer: enquanto que, em Cassirer, Rousseau podia ser declarado o precursor solitário de Kant porque lhe foi atribuído um esforço vitalício pela elaboração do lado ativo e autolegislador da vontade humana, nas interpretações mais recentes que retomam a proposta de Dent o nexo interno de seus textos é visto na tese diametralmente oposta segundo a qual a vontade humana, tanto em sentido positivo quanto negativo, depende da confirmação e estima por parte de outros sujeitos.

$\mathrm{Na}$ sequência, pretendo retomar essa segunda concepção para, inicialmente, mostrar sua legitimidade, mas também, num passo seguinte, seus limites; pois gostaria de mostrar que, durante toda a sua vida, Rousseau estava incerto demais acerca da importância efetiva do reconhecimento intersubjetivo na estrutura da sociedade para poder fazer dela, inequivocamente, o fundamento de toda a sua teoria. Concretamente, pretendo proceder de tal modo que, num primeiro passo, acompanharei Rousseau inicialmente em seu desenvolvimento teórico até o ponto em que, diante do espelho contrastante das formas deletérias de realização do "amor próprio", ele se tornou consciente das exigências de uma forma sociocontratual, igualitária do reconhecimento mútuo (1). A partir daqui se pode, então, ter presente sem dificuldade a enorme influência que a ideia bipolar de Rousseau a respeito do reconhecimento social exerceu sobre o discurso filosófico da modernidade; sua variante negativa, a profunda necessidade dos seres humanos de sobrepujar os respectivos cossujeitos no grau de estima social, é reinterpretada por Kant, em seus esboços de filosofia da história, como força motriz do progresso cultural e social, e sua variante positiva, o respeito mútuo entre iguais, é desenvolvido por Fichte e Hegel na

2 Cf. minha recensão (Honneth, 2012); independentemente de Neuhouser, Barbara Carnevali (2012) também empreendeu uma tentativa de interpretar Rousseau como teórico do reconhecimento. Sou grato a ela por sugestões e questionamentos críticos sobre este texto. 
direção de uma teoria do reconhecimento relacionada ao direito e à moralidade (2). Só no terceiro passo passarei, então, a tematizar o ceticismo com que Rousseau sempre - mas com intensidade crescente principalmente perto do fim de sua vida - viu a dependência de outros contida no "amour propre"; nos escritos tardios, ele brinca mais uma vez, assim como já no Segundo discurso, com a ideia de que, para a paz da alma humana de modo geral, talvez fosse vantajoso se tornar inteiramente independente da consideração do reconhecimento intersubjetivo. Neste sentido, na obra de Rousseau dois grandes motivos filosóficos se encontram em conflito constante: a ideia estoica de uma independência pessoal de toda avaliação alheia e a ideia intersubjetivista de uma profunda dependência do outro (3).

Em nenhum outro tema aparece de maneira mais plástica o motivo a partir do qual Rousseau chega, inicialmente, a seu conceito central do "amor próprio" do que em sua crítica inicial do teatro. Já no Primeiro discurso, aquilo que ele chama, muitas vezes depreciativamente, apenas de "fazimento de conta", é submetido a uma análise extremamente negativa (Rousseau 1750[1978c]), mas essa confrontação crítica só é consumada na Carta a d'Alembert (Rousseau, 1758[1978d]), que tem a extensão de um ensaio. Para Rousseau, o teatro não representa uma instituição cultural entre outras, em que um público esclarecido aprende a se confrontar, pela assistência ou pelo envolvimento, com obras de arte; o palco e a sala de teatro constituem, para ele, um caso especial na medida em que neles o comportamento exibido pelos atores pode passar para o público e infectar o indivíduo com o vírus da "mera aparência". Diferentemente do museu ou da sala de concertos, nos quais o público pode ao menos imaginar, na obra de arte apresentada, a intenção autêntica do respectivo artista, para Rousseau no teatro os espectadores inicialmente se confrontam apenas com formas de comportamento através das quais os atores querem revelar com que habilidade conseguem "assumir um caráter diferente de seu próprio" (ibid., p. 414); com isso, porém, o público ainda inocente é levado a se exercitar em gestos e formas de expressão que servem tão somente à autodissimulação. Dessas reflexões críticas Rousseau tira a abrangente conclusão de que a instituição de casas de teatro causa grande prejuízo a toda coletividade republicana, pois o que seria necessário em termos de atitudes mentais e formas de comportamento para tal estado baseado na vontade política do povo - cumprimento dos deveres, honestidade e orgulho cidadão - seria justamente minado pelas artes da dissimulação oferecidas no teatro; em consonância com isso, ele diz, na Carta a d'Alembert, 
que o ator desenvolve "a capacidade de enganar as pessoas para todas as profissões". ${ }^{3}$

Entretanto, Rousseau acredita que o perigo de contágio que provém da representação oferecida no palco apenas acentua adicionalmente uma tendência cultural que já se espalha com veemência nos mais diversos lugares em sua época. Já em seu Segundo discurso, publicado três anos antes da carta sobre o teatro, o Discurso sobre a origem e os fundamentos da desigualdade, ele tinha empreendido a tentativa de analisar genealogicamente aquelas novas formas de comportamento da dissimulação pretensiosa e do afã de prestígio que ele presenciava em Paris de modo particularmente drástico. No esforço de encontrar as raízes antropológicas de tais formas de busca de prestígio individual, apenas intensificadas pelo teatro, ele tinha topado, em seu escrito, com uma espécie particular de autorrelação humana que não considerava de origem natural, mas que, por causa de sua disseminação cultural, parecialhe conter traços de certa maneira naturais. O termo que Rousseau escolhe para chamar essa forma de comportamento transformada em segunda natureza é "amour propre"; ele constitui não só o fundamento de toda a sua crítica da sociedade, mas também a chave para uma compreensão de toda a sua contribuição para a fundamentação de uma teoria do reconhecimento intersubjetivo.

No raciocínio genealógico do Segundo discurso, o "amor próprio" não aparece num lugar tão proeminente quanto teria, a rigor, exigido sua importância central para toda a construção do estudo. Por certo Rousseau menciona o termo ocasionalmente, quando trata da identificação das causas mais profundas do surgimento da desigualdade social (1755[2008, p. 140-141, 148-149, 192-193, 206-207]), mas no fundo ele reserva sua explicação para uma única observação mais longa, cujo peso, por isso, dificilmente pode ser superestimado. Aqui, na observação 15 do texto (ibid., p. 368-373), o significado do "amour propre" é esboçado em contraposição ao "amour de soi-même", ao amor de si mesmo, sendo que toda a atenção é dirigida às diferenças no critério de avaliação pressuposto em cada caso: enquanto que o "amor de si", que Rousseau compreende como uma predisposição natural do ser humano, é uma espécie de autointeresse, que assegura a sobrevivência do indivíduo fazendo com que ele confie unicamente nos critérios próprios, vitais do bom e do correto, no "amor próprio", que se acrescenta mais tarde e é, neste sentido, artificial, esse critério do autointeresse se modifica de tal

3 Ibid., p. 415; quanto à crítica do teatro de Rousseau e suas consequências para sua compreensão de democracia, cf. o excelente estudo de Juliane Rebentisch (2012, cap. 5). 
modo que a opinião dos outros se torna a norma do comportamento oportuno. Rousseau explica essa diferença do modo mais expressivo em sua observação quando emprega a formulação - decerto tirada da teoria da moral de Hume, mas que já aponta para a frente, para Adam Smith - de que no sentimento ou na busca do "amor de si" o sujeito só conhece "a si mesmo como o único espectador", enquanto que no "amor próprio" ele vê os outros como "juízes" sobre o que faz e deixa de fazer (ibid., p. 369). Se as diferenças entre as duas formas do autointeresse são explicadas dessa maneira, por enquanto ainda não está de modo algum claro por que, afinal, uma tendência ao negativo ou problemático estaria associada à segunda postura, à do "amour propre"; pelo contrário, a partir da perspectiva de Adam Smith, por exemplo, poderse-ia dizer que uma orientação da própria ação pelo juízo internalizado dos outros - que o são, de início, apenas externamente - seria muito superior, em termos de circunspecção e adequação, à ação meramente autorreferencial. ${ }^{4}$ Em seu comentário, porém, Rousseau visa a um componente inteiramente distinto dessa autoavaliação intersubjetivamente mediada, que dificilmente parece ainda compatível com os efeitos salutares do "observador imparcial" na Teoria dos sentimentos morais: para Rousseau, o outro que se tornou “juiz" não é uma instância de correção dos próprios juízos, não uma força útil de descentração cognitiva e moral, mas uma fonte constante do impulso de precisar provar que se é superior às demais pessoas. O que o "amour propre" representa inicialmente no Segundo discurso é uma forma de autointeresse que se torna o estímulo de uma busca de prestígio social pelo fato de tornar a ação necessária para a própria sobrevivência dependente do parecer de outras pessoas.

Entretanto, ao se olhar a questão mais de perto, não é nada fácil descobrir exatamente o ponto em que Rousseau, em sua descrição da importância do observador internalizado, diverge da análise proposta poucos anos depois por Adam Smith, pois ambos visam inicialmente à mesma coisa na medida em que afirmam, a respeito do ser humano socializado, que, ao avaliar a adequação de seu comportamento, via de regra ele se orienta pelo juízo presuntivo de um outro generalizado. Mas uma diferença que acaba sendo séria em sua consequência consiste no fato de Rousseau acrescentar ainda a essa relação dual entre sujeito e observador interno uma outra relação que ocorreria porque,

4 Cf. Smith (1759[2004, p. 167]): "Nós nos esforçarmos para examinar nosso comportamento assim como, em nossa opinião, qualquer outro observador justo e imparcial o examinaria. Quando nos colocamos na situação dele e ainda compartilhamos interiormente de todos os afetos e motivos que determinaram nosso comportamento, aprovamos esse comportamento por simpatia com a aprovação desse juiz justo que criamos mentalmente." 
além disso, também as pessoas realmente presentes observam o sujeito que se orienta por seu "juiz" intersubjetivo; confrontado com ambas as perspectivas, o respectivo sujeito, segundo Rousseau, é levado a se apresentar diante de seu observador interno de tal maneira que pareça superior diante de seus cossujeitos presentes. Neste sentido, o "amour propre", diferentemente da autoavaliação que acontece quando o sujeito se coloca na perspectiva do "observador imparcial", é expressão de uma tripla estrutura relacional do ser humano socializado: tão logo o indivíduo, em consequência das interações que vão se tornando mais densas, aprendeu a orientar seu comportamento pelo juízo do outro generalizado, ele se esforçará, ao mesmo tempo, por se apresentar de modo tão favorável quanto possível diante dele, para, segundo sua própria avaliação, poder ter mais prestígio aos olhos de seus contemporâneos. $\mathrm{O}$ aspecto pérfido dessa dependência do juízo de outros não consiste, para Rousseau, como ele deixa repetidamente claro, na circunstância de que nesse caso alguém finge ter propriedades das quais, de fato, segundo seu próprio conhecimento, ele não dispõe; o que é fatal no "amor próprio", do ponto de vista de Rousseau, é, antes, que ele faz com que o sujeito se engane a respeito de si mesmo, porque ele precisa poder se apresentar não só externamente, diante das demais pessoas, mas diante de seu próprio juiz interno como uma pessoa com atributos tão favoráveis quanto possível - o que o indivíduo busca ao tentar satisfazer seu "amor próprio", não é simplesmente estima social, mas autoestima, portanto uma consciência do próprio valor (cf. Neuhouser, 2012, p. 53-54).

Tudo o que Rousseau diz sobre as patologias sociais de sua época tem suas raízes, segundo ele, nesse afã de prestígio que surge do "amour propre": na sociedade burguesa, as pessoas estão infatigavelmente ocupadas em obter atributos que, do ponto de vista de seu observador internalizado, lhe confiram um status que seja superior ao de seus contemporâneos. Depois de colocada em movimento, a "atividade impetuosa de nosso amor próprio", a "petulante activitité de nôtre amour propre" (Rousseau, 1755[2008, p. 192-193]), não tem mais limites, pois, por causa de seu caráter meramente relativo, faz com que toda característica distintiva se gaste rapidamente e, por isso, obriga a fazer esforços sempre novos de demonstrar de maneira crível a própria superioridade: o que ontem ainda podia ser tido como sinal de uma superioridade individual em termos de riqueza, poder ou beleza tem de ser superado hoje como consequência da disseminação social, de modo que em todos os campos da concorrência em torno do status impera uma tendência a um incremento constante da conduta distintiva (Neuhouser, 2012, p. 109-110). Nesse processo cultural o teatro assume, como vimos, apenas o papel intensificador 
de uma instituição de refinamento; Rousseau o detesta porque nele as cidadãs e os cidadãos aprendem formas de comportamento com as quais podem simular qualidades e características de status de maneira tão convincente que, no fim das contas, eles mesmos ainda ficam convencidos da autenticidade delas.

Mas já o Emílio, que Rousseau começa a escrever poucos anos após a publicação do Segundo discurso, deixa claro que ele não pretende se contentar com o diagnóstico meramente crítico do "amour propre"; aqui o mesmo termo reaparece várias vezes, sem estar associado de imediato e automaticamente com todas as conotações negativas que ainda lhe cabem no marco da crítica cultural. Se se acrescenta a esse escrito o Contrato social, que surge mais ou menos na mesma época e em que não se fala diretamente de "amour propre", mas de atitudes afins, esboça-se no pensamento de Rousseau um caminho que revela um esforço crescente de diferenciar cada vez mais o conceito que o orienta; insatisfeito por não poder mostrar uma saída das patologias da sociedade burguesa que expôs, o filósofo busca, a partir do início dos anos 1760, a possibilidade de poder afirmar, além da forma prejudicial, também uma forma salutar, socialmente compatível do "amor próprio". Mas para Rousseau não é nada fácil encontrar, partindo da definição formal inicialmente apenas negativa do "amour propre", um caminho para chegar a uma definição em que este de repente apareça positivamente; o que seria necessário para conseguir isso teria de consistir num esboço das condições sob as quais a obrigação de se comprovar superior aos demais sujeitos desaparecesse da autoavaliação socialmente mediada. No Emílio se encontra uma série de formulações que deixam plasticamente claro como Rousseau no começo apenas se esforça para empreender a difícil tarefa de fixar tais condições; em toda parte onde ele fala da inevitável formação do "amour propre" em seu pupilo, procura logo descobrir, como numa prescrição para um experimento, o que se deveria fazer para prevenir o perigo do afã de prestígio que geralmente resulta disso (cf. Rousseau, 1762[1998, p. 172, 179, 239-240]). A solução que Rousseau finalmente reserva para seu problema consiste num conselho que, à primeira vista, ainda parece muito enigmático: "Se estendermos o amor próprio [amour propre] a outras pessoas", afirma ele, "nós o transformamos em virtude. Não existe coração humano em que essa virtude não deitasse raízes" (op. cit., p. 261). Essa formulação passa a fazer sentido quando se percebe que uma "extensão" do "amour propre" significaria ver toda outra pessoa orientar sua própria ação de igual maneira pelo juízo de um observador generalizado; se essa mudança de perspectiva ocorrer, parece estar dizendo Rousseau, se, portanto, reconhecermos em todos os demais sujeitos essa busca 
de confirmação diante de seu juiz interior, desaparece também a motivação para querer superá-los em termos de prestígio e status. Esse raciocínio pode ser expresso com mais clareza ainda se, em vez de falar de "juiz interior", se disser que os sujeitos dependem de igual maneira de uma aprovação generalizada por parte da sociedade que os circunda. Falar de uma extensão do "amor próprio" não significa, então, outra coisa do que atribuir aos sujeitos a percepção de que necessitam do reconhecimento social uns dos outros e, por isso, deveriam abrir mão de uma busca concorrencial de prestígio mais elevado. Rousseau procura evitar um envenenamento do "amour propre" em seu pupilo Emílio tentando ensinar-lhe que, face à dependência de reconhecimento social de todas as pessoas, ele deve se contentar com um prestígio social em que se expresse justamente essa dependência recíproca. A fórmula em que se pode resumir uma forma assim temperada de reconhecimento social e que também reproduz adequadamente a proposta de solução de Rousseau é "respeito entre iguais". 5

Se se sintetiza o tratamento pedagógico do "amor próprio" no Emílio dessa maneira, também se pode entender pela primeira vez por que Rousseau pode, afinal, ser visto atualmente como um teórico do reconhecimento. Desde o início, portanto já no Segundo discurso, o conceito de "amor próprio", ao que tudo indica, pretendia designar mais do que apenas a paixão humana de se mostrar socialmente superior a outros e, por isso, de lutar constantemente por um grau mais elevado de estima; essas formas do afã de prestígio, por sua vez, baseiam-se na mola propulsora da necessidade de ser visto pelos membros da sociedade como alguém e, por conseguinte, de desfrutar de uma espécie de valor social. Portanto, antes de o "amour propre" se converter em desejo de prestígio e estima especial, ele possui, portanto, a forma inteiramente inocente que, mais tarde, também caberá à adoção da perspectiva do "observador interno" em Adam Smith; ${ }^{6}$ sua essência consiste em fazer com que, em nossa autoavaliação e autoimagem, nos tornemos dependentes do reconhecimento social da sociedade circundante. Para Rousseau, a forma negativa de uma comparação e um ímpeto de superioridade compulsivos só é assumida por essa dependência do "outro generalizado" quando deixa de existir a consciência concomitante de que todos nós compartilhamos a mesma carência de confirmação e aprovação social, pois então deixamos de perceber que somos nós mesmos que, junto com todos os outros membros da sociedade, constituímos aquela instância de

5 Quanto a essa "forma igualitária" do "amor próprio", retomando a monografia pioneira de Dent, cf. Joshua Cohen (2012, p. 101-104) e Frederick Neuhouser (2012, p. 83-101) com uma crítica à concepção de Cohen.

6 Quanto ao "reconhecimento" na obra de Adam Smith, cf. Christel Fricke et al. (2005), principalmente os ensaios de Stephen Darwall e Robert C. Solomon. 
um "juiz interno" da qual esperamos aprovação para nosso comportamento. Neste sentido, é coerente que Rousseau, em seu escrito sobre a educação, aconselhe medidas pedagógicas com cuja ajuda se possa transmitir à nova geração, já cedo, uma consciência de igualdade social, pois só se o indivíduo aprender a se entender como igual entre iguais, ele poderá, ao mesmo tempo, compreender-se como participante ativo daquele "outro generalizado" de cujo juízo ele depende para satisfazer seu "amor próprio".

Ora, esta última formulação já foi, evidentemente, escolhida no sentido de antecipar a construção com a qual Rousseau procura resolver o problema do "amour propre" no Contrato social. No Emílio já se encontra a ideia de satisfazer a ânsia por reconhecimento social por meio de um respeito entre iguais, mas ainda não a ideia de muito maior alcance de que, com isso, o indivíduo pode se compreender, ao mesmo tempo, também como coautor dos juízos sociais dos quais ele permanece, a partir de então, dependente em sua autocompreensão. No conceito de "volonté générale", com o qual Rousseau coroa seu esboço de contrato social, ele procura, pelo visto, delinear a noção de tal critério de avaliação do reconhecimento social gerado pelos próprios atingidos. Segundo este raciocínio, os cidadãos (e as cidadãs) de uma coletividade republicana não estão mais sujeitos, em seu sentimento de valor próprio, a uma instância do "outro generalizado" que lhes é estranha, porque chegaram previamente a um consenso, num ato de concordância espontâneo, quanto a uma vontade comum ou geral à luz da qual podem se reconhecer mutuamente, de agora em diante, da maneira que, coletivamente, julgarem correta. ${ }^{7}$ Rousseau parece crer que de uma tal forma de sociedade desapareçam todos aqueles critérios do valor individual incontroláveis, meramente impostos ao indivíduo, que até agora eram responsáveis pelas incitações viciosas do "amor próprio"; o que resta em vez disso são fontes puramente autoimpostas e transparentes de reconhecimento social que, em última análise, só podem conter a característica de que os membros da sociedade se respeitam uns aos outros exclusivamente como membros livres e iguais.

Entretanto, os capítulos finais do Contrato social também indicam que o próprio Rousseau não estava inteiramente convencido de que o "amour propre" se satisfaria inteiramente apenas no respeito recíproco, pois o que ele expõe sobre a "religião civil" e o patriotismo republicano parece querer dizer que o indivíduo sempre anseia por um sentimento mais forte do próprio valor

\footnotetext{
As restrições normativas que Rousseau impõe à "vontade geral” também podem, sob essa perspectiva, ser entendidas no sentido de que visam, eliminando assimetrias básicas em termos de poder social, impedir o indivíduo de obter estima às custas da liberdade de outros (Neuhouser, 2012, p. 221-226).
} 
do que aquele que pode obter tão somente por meio do reconhecimento como cidadão livre e igual. ${ }^{8}$ No "amor próprio", na necessidade de ser tido como alguém de valor aos olhos dos outros membros da sociedade, pululam ainda, mesmo que ela seja satisfeita igualitariamente, pretensões que vão além disso e são de difícil satisfação. Segundo Rousseau, ao que tudo indica elas tornam necessário buscar recursos adicionais de reconhecimento social dentro de uma coletividade republicana (cf. Neuhouser, 2012, p. 227-233); também estes não devem oferecer quaisquer pontos de referência para o perigo facilmente inflamável do afã de prestígio e, portanto, ser socialmente generalizáveis em grau suficiente, mas deveriam, tanto quanto possível, oferecer ao indivíduo a oportunidade de desfrutar, de modo virtuoso, de uma estima especial. Para Rousseau, a religião civil, o patriotismo democrático e, de maneira geral, todas as formas de orgulho constitucional coletivo constituem tais fontes de energia do reconhecimento social que complementam a "vontade geral"; como outros representantes ilustres da tradição republicana - Montesquieu e Tocqueville, por exemplo, para mencionar apenas dois deles -, ele pressupõe que mesmo sociedades democráticas se encontram diante da tarefa permanente de abrir margens de satisfação suficientes para a necessidade individual de reputação e estima. ${ }^{9}$ Antes, porém, de abordar esse complicador adicional da teoria do reconhecimento de Rousseau, gostaria de expor inicialmente a enorme importância que sua tematização do "amour propre" teve para as discussões subsequentes na filosofia da modernidade; muitos dos aspectos que ele tinha distinguido em seu conceito-chave ao longo do tempo foram retomados e aprofundados de maneira autônoma por pensadores que se seguiram a ele.

\section{2}

Se temos presente os aspectos semânticos muito distintos de que já tomamos conhecimento até agora no conceito de "amor próprio" de Rousseau, não podemos nos surpreender com o fato de que, no transcurso posterior do desenvolvimento da filosofia, as mais diversas consequências foram tiradas dele. Dependendo de a reflexão se apoiar mais no polo negativo do mero afã de prestígio ou mais no polo positivo do reconhecimento igualitário, ele se prestava a fundamentar diagnósticos com interesses praticamente opostos. A

\footnotetext{
Além de algumas passagens no Emílio às quais Neuhouser (2012, p. 97) remete, pode-se mencionar aqui, sobretudo, o capítulo sobre a "religião civil" no Contrato social, que exalta as vantagens de um estado que satisfaça "o amor ardente à glória e à pátria" (Rousseau, (1762[2003, p. 140-153, citação à p. 149]).

9 Cf. o estudo de Sharon R. Krause (2002) dedicado a Montesquieu e Tocqueville. Infelizmente, essa ótima investigação quase não dá atenção à obra de Rousseau porque a vincula, desde o início, unilateralmente a uma única versão do "amour propre" (ibid., p. 60).
} 
grande multidão dos seguidores de Rousseau certamente retomou o programa político do Contrato social, mas sem se dar conta de sua proveniência da complicada reinterpretação do conceito de "amour propre" que, inicialmente, só foi empregado de modo pejorativo; outros seguidores do filósofo francês, por sua vez, referiram-se exclusivamente ao Segundo discurso, mas em seus diagnósticos pessimistas de sua época lhes faltou qualquer perspectiva daqueles antídotos terapêuticos que só foram desenvolvidos nos textos posteriores. Mas também havia pensadores que estavam intuitivamente conscientes de todo o alcance desse conceito central para Rousseau e, por isso, decerto também conseguiam pressentir o nexo interno entre seus textos, que eram difíceis de unificar. Dessas exceções um tanto raras na história da interpretação de Rousseau deve ter feito parte Immanuel Kant. Na obra de Kant, o termo "amor próprio" aparece, dependendo da intenção cognitivo-filosófica que está sendo perseguida, tanto em seu significado positivo quanto negativo, sendo que as diferenças transparecem já na escolha das palavras. Pode-se perguntar se Kant de fato já percebeu adequadamente a concatenação sistemática de ambos os aspectos semânticos na carência de reconhecimento do ser humano, mas isso é de relevância secundária aqui em comparação com a circunstância admirável de que ele estava suficientemente familiarizado com as duas formas de emprego desse conceito para poder usá-las deliberadamente para seus próprios fins.

É suficientemente conhecido, naturalmente, o quanto em termos de estímulos teóricos Kant deve à noção desenvolvida por Rousseau de que só se podem considerar válidas as leis gerais que todo indivíduo pode compreender, por si, como estabelecidas por ele próprio. Mesmo a consequência daí resultante de que tal procedimento comum de autolegislação leva a um relacionamento de reconhecimento igualitário entre os participantes foi compartilhada por Kant com seu exemplo vitalício e expressa no conceito de "respeito". ${ }^{10}$ Menos conhecido, entretanto, é o fato de que Kant não só retoma a reinterpretação positiva do "amour propre" de Rousseau, mas também prevê um lugar exatamente definido para empregá-la; além de muitas referências ao papel antropológico do amor próprio comparativo, que contêm inequivocamente a marca conceitual de Rousseau, ${ }^{11}$ sobretudo dentro de seus

\footnotetext{
${ }^{10}$ Essa influência de Rousseau sobre a filosofia da moral de Kant ainda se esboça claramente na obra da fase inicial de Kant intitulada Vorlesung über Ethik [Preleção sobre a ética] (1990; cf. Kühn, 2003, p. 160-162), mas se dilui a olhos vistos com a passagem para a doutrina dos dois mundos, embora percepções básicas sejam mantidas; quanto à questão toda, cf. Jerome Schneewind (1998, p. 487-492).

${ }^{11}$ Cf., de modo exemplar e particularmente marcante, Immanuel Kant, Die Religion innerhalb der Grenzen der bloßen Vernunft [A religião dentro dos limites da pura razão] (1968a, v. 8, p. 647-879).
} 
esboços sobre a filosofia da história se expressa sistematicamente uma ideia do afã de prestígio social para a qual ele só pode ter sido estimulado por uma leitura intensiva do Segundo discurso. A tarefa que o conceito puramente pejorativo de "amour propre" aí desenvolvido recebe na filosofia da história de Kant resulta do objetivo que ele se estabeleceu com ela no conjunto de sua obra: ela deve fazer com que não desesperemos em relação à validade apenas transcendental, portanto empiricamente ineficaz, das leis morais esboçando tentativamente, com a ajuda da faculdade do juízo, uma imagem da história humana que contenha indícios suficientes de um progresso para o melhor para, apesar de tudo, poder nos motivar e incitar em nossos esforços morais. ${ }^{12}$ Contudo, agora Kant precisa, para poder atingir o fim assim delineado, dotar seu esboço hipotético do transcurso da história de ao menos um número suficiente de indicadores de um progresso efetivo no âmbito moral para que esse esboço não perca toda e qualquer credibilidade para seus contemporâneos. E justamente nesse ponto de sua filosofia da história, onde o que está em pauta é a plausibilização empírica de uma progressão moral na história, se faz sentir, de modo até paradoxal, a concepção negativa de "amour propre" de Rousseau. Kant procura, inteiramente contra a intenção do Segundo discurso, dar ao afã de prestígio, que também é visto por ele aqui como constitutivo para a espécie humana, uma interpretação que visa tornar compreensível por que, no fim das contas, desse afã provêm efeitos voltados para uma melhoria moral: os sujeitos humanos, segundo o raciocínio de Kant em seu escrito Ideia de uma história universal de um ponto de vista cosmopolita (1968b, v. 11, p. 37-39), buscam sempre, com base em sua "sociabilidade insociável", destacar-se por meio de realizações para as quais possam encontrar o reconhecimento da comunidade social. A partir de um determinado limiar na história, porém, essa luta pela distinção baseada na vaidade atingiu um estágio em que aos sujeitos concorrentes não resta nenhuma outra possibilidade de aquisição de prestígio do que também procurar realizações especiais no comportamento e discernimento moral. Neste sentido, para Kant, aquilo que no início era apenas mero afã de estima pública acaba levando, no transcurso mais longo do desenvolvimento humano, também a um progresso na situação moral, de modo que, apesar de todas as restrições empíricas, podemos cobrar ânimo para melhorias adicionais no âmbito moral. Com isso, Kant unificou na sistemática de sua teoria, de certa maneira até engenhosamente, os dois polos semânticos do "amor próprio" cuja conexão interna na obra de Rousseau ele

${ }^{12}$ Quanto a isso, cf. Axel Honneth (2007, p. 9-27). Além disso, uma obra pioneira: Yirmiyahu Yovel (1980, p. 146-151) sem referência a Rousseau, mas remetendo a Hegel. 
possivelmente desconhecia: ao conceito positivo é atribuída, no significado do respeito recíproco entre iguais, a tarefa de explicar o ponto de vista normativo da dimensão moral, enquanto ao conceito negativo cabe a função de fornecer uma explicação hipotética para o caminho que leva a esse destino, portanto para o ponto de vista da moral. Poder-se-ia ainda ir um passo além e dizer que Kant solucionou simplesmente de maneira ontológica as dificuldades resultantes da duplicação do "amour propre" associando suas duas acepções às esferas distintas da realidade empírica, por um lado, e do âmbito numenal, por outro: no mundo causal da história humana, o autointeresse humano possui, então, a forma do afã de prestígio social, ao passo que, no mundo racional das leis morais, ele assumiu a forma do respeito moral.

Entretanto, uma solução singela como essa não podia convencer inteiramente nem o próprio Kant, pois, em seus esboços de filosofia da história, ele se esforçou justamente para criar um elo de ligação entre a história factual e a dimensão ideal e, com isso, impedir que o hiato entre os dois mundos ficasse grande demais. Neste sentido, é mais plausível atribuir a ele um desconhecimento geral da circunstância de que, ao menos para Rousseau, os dois impulsos do afã de prestígio e do respeito recíproco deveriam provir da mesma fonte motivacional, a saber do "amor próprio". Caso Kant de fato não estivesse ciente dessa conexão interna no pensamento de Rousseau, ele nem precisaria se preocupar em esclarecer as razões do deslocamento da carência humana subjacente para uma ou outra direção; ele teria, antes, encontrado nos escritos de seu grande modelo dois conceitos que, independentemente um do outro, pareciam-lhe explicativamente tão vigorosos do ponto de vista filosófico que tentou empregá-los em locais diferentes de sua obra.

Mais difícil ainda, porém, é avaliar a dependência em relação ao conceito de "amour propre" de Rousseau entre os pensadores que queriam superar a teoria filosófica de Kant imediatamente após sua morte com a intenção de evitar até mesmo o surgimento de um hiato entre os dois mundos: da causalidade empírica e da razão numenal. Pode-se dizer que ao menos Hegel, mas decerto também Fichte, estavam intuitivamente cientes da proveniência de suas próprias teorias do reconhecimento da herança do pensamento rousseauniano; embora, ao que me consta, Hegel não mencione o conceito de "amor próprio" em nenhuma passagem e assuma toda a terminologia do reconhecimento mais de Fichte, muitas observações em sua Filosofia do direito levam a concluir que ele se imaginou a moralidade, segundo o modelo da "volonté générale" de Rousseau, como o resultado de um reconhecimento mútuo de indivíduos que se restringem em sua 
subjetividade. ${ }^{13}$ Se, além disso, está claro para nós que também Hegel atribui a "vaidade" ou "hipocrisia" a um desconhecimento daquilo que une os sujeitos em termos de carência comum de reconhecimento, deve ser óbvio que há uma dependência em relação ao horizonte ideativo de Rousseau, se não direta, ao menos no tocante ao pensamento e à atmosfera. Como o grande francês, também o filósofo alemão percebe o afã de prestígio subjetivo e o reconhecimento mútuo, a vaidade e o respeito igual como dois lados de um anseio da subjetividade humana de ser tida como uma pessoa de valor social aos olhos dos demais sujeitos. ${ }^{14}$ Concretamente, entretanto, também no caso de Hegel, assim como no de Kant, é extremamente difícil apreender até que ponto chegou esse conhecimento do duplo significado do "amor próprio" na obra de Rousseau; ainda que na Filosofia do direito sejam feitas distinções entre formas decadentes e configurações bem-sucedidas da carência de reconhecimento que são semelhantes ao que faz Rousseau, é de se duvidar que tais diferenciações se devam diretamente a uma adaptação do conceito de "amour propre". Uma razão para as dificuldades das gerações seguintes de perceberem todo o alcance do conceito-chave de Rousseau pode residir inclusive no fato de que ele mesmo nunca se livrou de uma certa reserva para com a autorrelação designada por esse termo, pois até o fim de sua vida se debateu com a pergunta sobre se, de modo geral, para uma vida boa não seria mais aconselhável superar mentalmente a dependência de outros como tal.

Se lançarmos um olhar retrospectivo sobre o que descobrimos antes dessa observação intermediária de caráter histórico-teórico a respeito do "amor próprio" no pensamento de Rousseau, chama a atenção, além do enorme alcance do conceito, o traço de uma inquietação contínua que lhe é, ao mesmo

\footnotetext{
${ }^{13}$ Quanto à influência do Contrato social de Rousseau sobre ao desenvolvimento das ideias de Hegel até sua Filosofia do direito, cf. o excelente ensaio de Hans Friedrich Fulda (1991, especialmente p. 62ss); cf. também Patrick Rilley (2001, p. 124-153). Pode-se afirmar que também Fichte se explica a proveniência transcendental da relação jurídica seguindo o modelo rousseauniano da "vontade geral"; cf. o artigo muito interessante de Georg Gurwitsch (1922). Nenhuma dessas contribuições, entretanto, discute a dependência da própria percepção de Rousseau acerca do "amor próprio"; tenho a impressão de que a oportunidade de aprofundar esses nexos remissivos mais profundos só é inaugurada pela monografia de Frederick Neuhouser.

${ }^{14}$ Essa cisão do reconhecimento fica muito clara nas passagens de sua Filosofia do direito em que Hegel $(1970$, v. 7, § 253) compreende o afã de prestígio individual como consequência de um fracasso da situação estabelecida de reconhecimento "moral". De resto, não me parece errado, por conseguinte, entender o esboço hegeliano de uma economia de mercado moralmente circundada como resposta ao diagnóstico rousseuniano da decadência da sociedade burguesa, conforme a proposta de Jeffrey Church (2010).
} 
tempo, inerente: o autointeresse mediado pelos outros que é representado pelo "amour propre", à diferença do mero "amour de soi" não perde, para Rousseau, seu caráter desmedido e insaciável nem mesmo quando, graças à percepção da dependência comum, tenha assumido a forma de um respeito mútuo entre iguais. Como ressaltou principalmente Frederick Neuhouser (2012, p. 96-101), o realismo antropológico de Rousseau implica que, segundo ele, mesmo após a perda do amor próprio complacente, o indivíduo mantém um anseio constante de ser reconhecido como um indivíduo particularmente destacado no seio de sua comunidade; por conseguinte, o ser humano socializado não pode se satisfazer em ser tido apenas como um igual entre iguais na coletividade republicana, mas precisa, indo além disso, almejar a uma estima social referente a capacidades e qualidades que, por sua vez, distinguem-no de todos os outros. ${ }^{15}$ A razão desse excedente na busca de reconhecimento, que obriga Rousseau a, no Contrato social, procurar fontes adicionais da comprovação e reputação pessoal, tem a ver, em última análise, com a estrutura da autorrelação pela qual o "amour propre" se caracteriza: já que, em tal postura, perdemos todos os critérios de autoavaliação que, por assim dizer, provêm de nossa carência natural, só conseguimos ainda avaliar nossos verdadeiros méritos e qualidades no espelho das pessoas que, em seu conjunto, formam a "opinião pública" ou o "outro generalizado". A insegurança quanto a se, à luz desses juízos públicos, nossas realizações são de fato apreciadas adequadamente continuará existindo mesmo quando, como coautores da "volonté général", participamos com outros do surgimento dos critérios valorativos de validade geral; por isso, para prevenir possíveis avaliações errôneas de nossa personalidade, somos obrigados, mesmo sob condições de respeito igual, a almejar um reconhecimento que nos faça sobressair em relação a todos os outros. Diferentemente de Adam Smith, que conseguia se imaginar o observador externo como generalizável a ponto de perder todos os traços do arbitrário e até coincidir com a razão como tal, ${ }^{16}$ Rousseau não pode acreditar numa racionalizibilidade tão completa do juiz geral; para ele, o juízo alheio ao qual o indivíduo está exposto na autorrelação do "amour propre" encerra sempre tão fortemente o perigo do desconhecimento

15 Em meu estudo Luta por reconhecimento (1992, cap. 2), designei essa outra forma de reconhecimento, que não visa ao respeito igual, mas ao destaque individual, com a categoria "estima", retomando Hegel e George Herbert Mead; ao fazer isso, apoiei-me, como o fez Neuhouser mais tarde, num famoso artigo de Stephen L. Darwall: Two kinds of respect (1977).

${ }^{16}$ Existem passagens em que Adam Smith (1759[2004]) se imagina o "juiz imparcial" como a tal ponto generalizável que ele se torna o "representante de Deus em nós" (p. 250) e até coincide com os axiomas da "razão" (p. 203); Kant pôde retomar isso para dar uma interpretação transcendental a essa suma de regras racionais. Quanto à importância da teoria da moral de Smith nesse contexto, cf. Ernst Tugendhat (1993, p. 282-309). 
que ele vê uma busca precauciosa de valorização especial não só como algo amplamente disseminado, mas também culturalmente justificado.

Por outro lado, para Rousseau o risco do desconhecimento - que designa não simplesmente um menosprezo de méritos individuais, e sim o fato de não se tomar cognitivamente conhecimento deles - permanece também um constante motivo de inquietação; o verdadeiro perigo provocado com a passagem histórico-civil do "amour de soi" para o "amour propre", para ele, não é que o entorno social possa se enganar a respeito da verdadeira natureza do indivíduo e nem consiga perceber aptidões especiais. ${ }^{17}$ Nesse diagnóstico, que constitui um elemento central da teoria rousseauniana do reconhecimento que pode facilmente passar despercebido e só se destaca com mais clareza mais tarde, os pontos de referência da dependência em relação ao outro se deslocaram imperceptivelmente da dimensão moral para a epistêmica: a instância internalizada da opinião pública da qual o indivíduo depende em termos de sua autovaloração não aparece mais como um juiz moral, mas como um juiz teórico, que deve emitir um juízo sobre que qualidades um indivíduo possui de fato. Com esse deslocamento muda, naturalmente, também o tipo de comportamento para o qual o sujeito é estimulado, em cada caso, na postura do "amor próprio": ao passo que ele precisa poder demonstrar seu valor social e suas capacidades individuais enquanto o "outro generalizado" constitui uma instância moral, no caso da interiorização de um juiz epistêmico ele tem de provar de quais méritos e qualidades realmente dispõe.

Olhando-se seus textos, pode-se considerar um tanto improvável que Rousseau tenha se dado suficientemente conta dessa oscilação entre uma compreensão moral e epistêmica do "amour propre". Em toda parte onde ele trata do vírus do afã de prestígio e recomenda como terapia uma atitude mental republicana de respeito igualitário, certamente prepondera uma noção normativa do outro generalizado; mas tão logo passa a falar da desgraça propriamente dita da dependência em relação ao outro, muitas vezes o modelo epistêmico se desloca de repente para o primeiro plano. Nessa forma de uma instância internalizada, não da valoração moral, mas da avaliação teórica, o "amor próprio" de Rousseau exerceu uma influência enorme sobre o desenvolvimento da filosofia francesa; chegando até Sartre e Lacan; encontram-se aí restos da

${ }_{17}$ Tais manifestações em que Rousseau descreve a estrutura intersubjetiva do "amor próprio" como uma dependência de constatações factuais sobre os próprios traços de comportamento e qualidades se multiplicam nos escritos mais tardios, de coloração autobiográfica. Para documentar isso, cito apenas uma frase de seu texto, publicado postumamente, Rousseau richtet über Jean-Jacques [Rousseau juiz de Jean-Jacques] (1978a, p. 253-636, neste caso p. 259, grifo meu): "Haverá ele de gloriar-se de qualidades que realmente possui, mas que ninguém quer perceber nele?" 
noção de que com a dependência do reconhecimento social está vinculada inalteravelmente a circunstância de não ser percebido "cognitivamente" no cerne da própria subjetividade. ${ }^{18}$ Para Rousseau, porém, a noção epistêmica de um "juiz interno" dá constantemente ensejo de se ocupar teoricamente com a alternativa radical de superar inteiramente a autorrelação do "amour propre"; sobretudo seus textos de matiz autobiográfico giram constantemente em torno da possibilidade de recuperar uma atitude individual para a qual o reconhecimento social dos próprios méritos e capacidades tenha perdido toda e qualquer importância existencial. Em tais reflexões se reflete um motivo estoicista no pensamento de Rousseau que se encontra inequivocamente em contradição com sua concepção, até agora apresentada, segundo a qual, como seres socializados, nós necessitamos obrigatoriamente do reconhecimento de nosso valor social.

Se examinarmos os escritos em que Rousseau tematiza a própria autorrelação, menos as Confissões quanto, principalmente, o estudo - revelador já a partir do título - Rousseau juiz de Jean-Jacques (1978a) e os Devaneios de um andarilho solitário (1978b), chama a atenção, inicialmente, o quanto se renega neles toda e qualquer dependência do juízo de outras pessoas; aqui, o caminho de uma vida boa e correta é caracterizado de tal modo que consiste na busca constante de um equilíbrio interior que só pode surgir caso não se dê mais atenção ao comportamento avaliativo do entorno social. ${ }^{19} \mathrm{O}$ próprio fato de Rousseau só querer ele mesmo julgar sobre seu alter ego significa que ele considera desejável um estado em que tenha me tornado independente de atribuições alheias e de juízos dos quais eu mesmo não posso dispor; para viver em paz comigo mesmo, minha autoestima e minha autoimagem só devem se dever a caracterizações de minha pessoa como cujo autor só eu mesmo possa me compreender. Como ameaça desse ideal de autarquia judicativa não aparece em primeiro lugar a dependência das valorações morais da opinião pública, mas a dependência em relação aos juízos dela sobre nossas qualidades e atividades, pois estes juízos nos induzem a que nos enganemos a respeito de nossa verdadeira natureza e, com isso, deixemos de perceber o que de

\footnotetext{
${ }^{18}$ Haveria necessidade de um texto em separado para documentar suficientemente essa tese a respeito de uma dependência profunda das correntes francesas da teoria do reconhecimento em relação ao modelo epistemológico de Rousseau. Limito-me aqui a indicar passagens em que se torna particularmente claro até que ponto Sartre, Lacan e outros pensadores franceses veem o perigo do desconhecimento "cognitivo" como consequência de todo reconhecimento: Jean-Paul Sartre (1993, p. 469-478 ["coisificação"]); Jacques Lacan (1986, p. 165-204, especialmente p. 183-184 ["desconhecimento"]); Pierre Boudieu (2001, p. 212 ["verdade"]).

19 Quanto à exposição e crítica dessas posições “estoicas”, cf. Avishai Margalit (1997, p. 39-44). Uma defesa incisiva é empreendida por Ernst Tugendhat (2003, especialmente caps. 2 e 4).
} 
fato temos de aptidões valiosas. Neste sentido, não pode causar surpresa que Rousseau, no famoso Quinto passeio de seus Devaneios (1978b), ${ }^{20}$ descreva como quintessência da felicidade existencial um estado em que o autor fica sabendo, numa mera observação passiva de processos naturais, que qualidades de fato ele tem e que preocupações realmente o afetam; já que a natureza não pode falar nem emitir juízos sobre nós, aí se tira de todo sentimento de "amor próprio" aquilo de que ele se alimenta, de modo que podemos conhecer a nós mesmos sem nos preocupar com outras pessoas.

Durante toda a sua vida, Rousseau, como deixam claro principalmente suas reflexões tardias sobre si mesmo, oscilou entre uma reafirmação decidida e uma rejeição radical da dependência existencial em relação ao outro; em sua obra se manifesta, por um lado, a percepção de que os seres humanos devem sua autoestima e capacidade de ação ao reconhecimento intersubjetivo, mas, por outro, já se registram as ameaças vinculadas a esse estar à mercê do juízo do entorno social. Mesmo que, em última análise, sua indecisão talvez se deva ao fato de não ter distinguido com suficiente clareza entre uma compreensão moral e epistêmica do reconhecimento, Rousseau inaugurou com ela um debate filosófico que não foi concluído até hoje; para ambas as posições por ele defendidas, a da passagem do "amour propre" para o reconhecimento simétrico e a da rejeição de toda dependência em relação ao "outro generalizado", encontram-se constantemente partidários resolutos. Por isso, o legado que Rousseau deixou para uma teoria do reconhecimento é altamente ambíguo; como no caso de um presente grego, as pessoas que aceitam esse legado e querem dar continuidade a ele também trazem sempre o inimigo para dentro da própria casa.

\section{Referências}

BOURDIEU, Pierre. Meditationen: zur Kritik der scholastischen Vernunft. Frankfurt am Main: Suhrkamp, 2001.

CASSIRER, Ernst. Das Problem Jean Jacques Rousseau. In: Ernst Cassirer; Jean Starobinski; Robert Darnton. Drei Vorschläge, Rousseau zu lesen. Frankfurt am Main: Fischer 1989, p. 7-78.

CARNEVALI, Barbara. Romantisme et reconnaissance: figures de la conscience chez Rousseau [original em italiano]. Genève: Droz, 2012.

CHURCH, Jeffrey. The freedom of desire: Hegel's response to Rousseau on the problem of civil society. American Journal of Political Science, v. 54, n. 1, p. 125-139, 2010.

${ }^{20}$ Uma interpretação brilhante desse capítulo central é proposta por Heinrich Meier (2011, v. 1, cap. 4). 
COHEN, Joshua. Rousseau: a free community of equals. Oxford: Oxford University Press, 2012.

DARWALL, Stephen. Smith über die Gleichheit der Würde und den Standpunkt der 2. Person. In: Christel Fricke; Hans-Peter Schütt (Orgs.). Adam Smith als Moralphilosoph. Berlin: De Gruyter, 2005. p. 178-189.

DARWALL, Stephen L. Two kinds of respect. Ethics, v. 88, n. 1, p. 36-49, 1977.

DENT, Nicholas J. H. Rousseau. Oxford: Routledge, 1988.

FRICKE, Christel; SCHÜTT, Hans-Peter (Orgs.). Adam Smith als Moralphilosoph. Berlin: De Gruyter, 2005.

FULDA, Hans Friedrich. Rousseausche Probleme in Hegels Entwicklung. In: Hans Friedrich Fulda; Rolf-Peter Horstmann, (Orgs.). Rousseau, die Revolution und der junge Hegel. Stuttgart: Klett Cotta, 1991. p. 41-73.

GURWITSCH, Georg. Kant und Fichte als Rousseau-Interpreten. Kant-Studien, v. 27, n. 1-2, p. 138-164, 1922.

HEGEL, Georg W. F. Grundlinien der Philosophie des Rechts. In: Georg W. F. Hegel. Werke in zwanzig Bänden (Theorie-Werkausgabe). Frankfurt am Main: Suhrkamp, 1970. v. 7.

HONNETH, Axel. Die Entgiftung Jean-Jacques Rousseaus: neuere Literatur zum Werk des Philosophen. Deutsche Zeitschrift für Philosophie, v. 60, n. 4, p. 611-632, 2012.

HONNETH, Axel. Die Unhintergehbarkeit des Fortschritts: Kants Bestimmung des Verhältnisses von Moral und Geschichte. In: Axel Honneth. Pathologien der Vernunft: Geschichte und Gegenwart der Kritischen Theorie. Frankfurt am Main: Suhrkamp, 2007. p. 9-27.

HONNETH, Axel. Kampf um Anerkennung: zur moralischen Grammatik sozialer Konflikte. Frankfurt am Main, 1992 [Luta por reconhecimento, Editora 34].

KANT, Immanuel. Vorlesung über Ethik. Frankfurt am Main: Fischer Taschenbuch, 1990.

KANT, Immanuel. Die Religion innerhalb der Grenzen der bloßen Vernunft. In: Immanuel Kant. Werk in zwölf Bänden (Theorie-Werkausgabe). Frankfurt am Main: Suhrkamp, 1968a. v. 8, p. 647-879.

KANT, Immanuel. Idee zu einer allgemeinen Geschichte in weltbürgerlicher Absicht. In: Immanuel Kant. Werk in zwölf Bänden (Theorie-Werkausgabe). Frankfurt am Main: Suhrkamp, 1968b. v. 11, p. 33-50.

KELLY, George Armstrong. Rousseau, Kant and History. Journal of the History of Ideas, v. 29, n. 3, p. 347-364, 1968.

KRAUSE, Sharon R. Liberalism with honor. Cambridge, Mass: Harvard University Press. 2002.

KÜHN, Manfred. Kant: eine Biographie. München: C. H. Beck, 2003.

LACAN, Jacques. Subversion des Subjekts und Dialektik des Begehrens im Freudschen Unbewussten. In: Jacques Lacan. Schriften II. [Ed. de Norbert Haas]. Weinheim: Quadriga, 1986. 
MARGALIT, Avishai. Politik der Würde: über Achtung und Verachtung. Berlin: Alexander Fest, 1997.

MEIER, Heinrich. Über das Glück des philosophischen Lebens: Reflexionen zu Rousseaus Rêveries in zwei Büchern. München: C. H. Beck, 2011.

NEUHOUSER, Frederick. Pathologien der Selbstliebe: Freiheit und Anerkennung bei Rousseau. Berlin: Suhrkamp, 2012 [orig.: Rousseau's theodicy of self-love: evil, rationality and the drive for recognition. Oxford: Oxford University Press, 2008].

REBENTISCH, Juliane. Die Kunst der Freiheit: zur Dialektik demokratischer Existenz. Frankfurt am Main: Suhrkamp, 2012.

RILEY, Patrick. Rousseau's general will. In: Patrick Riley (Org.). The Cambridge companion to Rousseau. Cambridge: Cambridge University Press, 2001. p. 124-153.

ROUSSEAU, Jean-Jacques. Diskurs über die Ungleichheit (1755). 6. ed. Paderborn: Schöningh, 2008. [Ed. em português: Discurso sobre a origem e os fundamentos da desigualdade entre os homens. Trad. de Lourdes Santos Machado. São Paulo: Abril Cultural, 1973. p. 207-326 (Os Pensadores, v. 24)].

ROUSSEAU, Jean-Jacques. Emil oder über die Erziehung (1762). 13. ed. Paderborn: Schöningh, 1998. [Ed. em português: Emílio ou Da educação. Trad. de Sérgio Milliet. São Paulo: Difel, 1979].

ROUSSEAU, Jean-Jacques. Vom Gesellschaftsvertrag oder Grundsätze des Staatsrechts (1762). Stuttgart: Reclam, 2003. [Ed. em português: Do contrato social: os princípios do direito político. Trad. de Lourdes Santos Machado. São Paulo: Abril Cultural, 1973. p. 7-151 (Os Pensadores, v. 24)].

ROUSSEAU, Jean-Jacques. Abhandlung über die Wissenschaften und Künste (1750). In: ROUSSEAU, Jean-Jacques. Schriften. München: Hanser, 1978c. v. 1, p. 27-60. [Ed. em português: Discurso sobre a ciência e as artes. Trad. de Lourdes Santos Machado. São Paulo: Abril Cultural, 1973. p. 329-436 (Os Pensadores, v. 24)].

ROUSSEAU, Jean-Jacques. Brief an d'Alembert über das Schauspiel (1758). In: JeanJacques Rousseau. Schriften. München: Hanser, 1978d. v. 1, p. 333-474.

ROUSSEAU, Jean-Jacques. Rousseau richtet über Jean-Jacques [Rousseau juiz de Jean-Jacques]. In: Jean-Jacques Rousseau. Schriften. München: Hanser, 1978a. v. 2, p. 253-636.

ROUSSEAU, Jean-Jacques. Träumereien eines einsamen Spaziergängers. In: JeanJacques Rousseau. Schriften. München: Hanser, 1978b. v. 2, p. 637-760.

SARTRE, Jean-Paul. Das Sein und das Nichts: Versuch einer phänomenologischen Ontologie. Reinbek bei Hamburg: Rowohlt, 1993.

SCHNEEWIND, Jerome B. The invention of autonomy. Cambridge: Cambridge University Press, 1998.

SMITH, Adam. Theorie der ethischen Gefühle (Theory of Moral Sentiments, 1759, ed. de Walther Eckstein). Hamburg: Felix Meiner Verlag, 2004.

SOLOMON, Robert C. Sympathie für Adam Smith: einige aktuelle philosophische und psychologische Überlegungen. In: Christel Fricke; Hans-Peter Schütt (Orgs.). Adam Smith als Moralphilosoph. Berlin: De Gruyter, 2005. p. 251-276. 
TUGENDHAT, Ernst. Vorlesungen über Ethik. Frankfurt am Main: Suhrkamp, 1993.

TUGENDHAT, Ernst. Egozentrizität und Mystik: eine anthropologische Studie. München: C. H. Beck, 2003.

YOVEL, Yirmiyahu. Kant and the Philosophy of History. Princeton: Princeton University Press, 1980.

Autor correspondente:

Axel Honneth

Grüneburgplatz 1 - IG 2.515

60629 Frankfurt am Main - Alemanha

Recebido em: 18 jul. 2012

Aprovado em: 15 out. 2012 